\title{
Teoria Democrática Contemporânea e Meios de Comunicação de Massa: uma discussão preliminar
}

\author{
Teoria Democrática Contemporânea e Meios de Comunicação de Massa: uma \\ discussão preliminar
}

\section{Teoria Democrática Contemporanea y Medios de Comunicación de Masa: una discusión preliminar}

João Paulo Jonas Almeida ${ }^{1}$

Gilberto Wildberger Almeida ${ }^{2}$

\begin{abstract}
Resumo
Este artigo tem como objetivo revisitar algumas das principais correntes teóricas contemporâneas de democracia, buscando apontar alguns dos motivos que as levaram a negligenciar os meios de comunicação em seus universos de reflexão. $O$ artigo se divide em três seções. A primeira seção introduz a problemática ao abordar as principais tensões que atravessam o sistema democrático em sociedades complexas. A segunda revisita algumas das principais formulações teóricas contemporâneas de democracia, buscando explicitar como a qualificaram. Por fim, a conclusão aponta para a necessidade de pensar a democracia em estreita ligação com o universo da comunicação pública.
\end{abstract}

Palavras chaves: teoria democrática contemporânea. Meios de comunicação de massa; comunicação pública; Cidadania.

\begin{abstract}
This article aims at revisiting some of the main theoretical contemporaneous approaches to democracy. It points out to some reasons that mass communications means were not taken into due consideration into political analysis. This article contains three parts. The first section brings the tensions and problems that stems on complex democratic societies. The second section bends over current theoretical formulations on democracy highlighting their quality aspects. Finally, the conclusion brings the linkages modern democracies shows with the universe of public communications.
\end{abstract}

Key words: Contemporaneous Democratic Theory. Mass communications. Public communications. Citizenship.

\section{Resumen}

Este artículo tiene por obyecto revisitar algunas de las principales vertientes contemporáneas de democracia, buscando poner en saliente algunos de los motivos que las llevaron a olvidar los medios de comunicación en sus reflexiones. El artículo está repartido en tres secciones. La primera sección introduce la problemática mientras los problemas y tensiones inherentes en sociedades complejas son abordados. La segunda sección revisita algunas de las principales formulaciones teóricas de democracia, explicitándolas como están calificadas. En la conclusión está apuntada la necesidad de pensarse la democracia en estrecha conexión con el universo de la comunicación pública.

\footnotetext{
1 Professor da Universidade Federal do Oeste da Bahia. Doutorando em difusão do conhecimento pela Universidade Federal da Bahia(UFBA). E-mail: jonasdealmeida@yahoo.com.br.

${ }^{2}$ Doutor em Comunicação pela Faculdade de Comunicação (FACOM) da Universidade Federal da Bahia (2000). E-mail: gwa1945@gmail.com.
}

Comun. \& Inf., Goiânia, GO, v. 21, n. 1, p. 51-69, jan./mai.. 2018 
Palabras clave: Teorías Contemporáneas de Democracia. Comunicación de masa. Comunicación pública; Ciudadanía.

\section{INTRODUÇÃO}

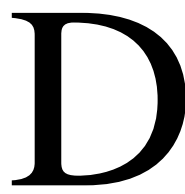

emocracia e justiça compõem, hoje, os dois grandes eixos em torno dos quais se estabelece a reflexão na teoria política (MIGUEL, 2015). É possível ainda afirmar de maneira sustentável, mesmo incorrendo em certo risco de simplificação, que a democracia é o horizonte normativo por excelência explícito ou implícito - de quase toda reflexão que se realiza na ciência política contemporânea (MIGUEL, 2014). Pensar democracia e justiça em sociedades complexas, no entanto, implica em lidar com uma série de problemas e tensões que a atravessam. Em primeiro lugar, e como característica fundamental e inescapável, nossas democracias são representativas, o que implica mesmo na impossibilidade ou, ao menos, na enorme dificuldade de operacionalizar formas de democracia direta. Isso se deve principalmente ao fato de que: (a) vivemos em Estados muito extensos, para que todos se reúnam, e muito populosos, para imaginar um diálogo que incorpore cada um de seus cidadãos; (b) as questões políticas são complexas e diversas demais para que se possa dispensar a especialização dos governantes; (c) a incorporação de uma variedade de grupos ao demos - trabalhadores, mulheres, imigrantes etc - ampliou a profundidade das clivagens em seu seio, tornando, assim, indispensável a existência de alguma forma de mediação (MIGUEL, 2014).

Por outro lado, a necessidade/exigência de representação política impõe novos e urgentes conjuntos de problemas (MIGUEL, 2014). O primeiro problema se refere a separação entre governantes e governados, isto é, a constatação de que as decisões públicas/políticas são de fato tomadas por um pequeno grupo de pessoas (elite) e não pela massa de pessoas que serão submetidas a elas. Isso implica em reconhecer e lidar com um paradoxo: a democracia é um governo do "povo" em que o "povo" não governa, isto é, não se faz presente no momento das decisões, a não ser de forma bastante mediada. Como notou Miguel (2014), a questão é que a categoria "povo" não é uma categoria econômica, como, por exemplo, "classe trabalhadora" ou “operariado": é uma categoria política que reúne as pessoas que estão submetidas a um governo. Nesse sentido, "povo" se opõe exatamente a governo: povo e governo são antípodas na relação de dominação política. "Um governo do povo é, assim, uma contradição em termos" (MIGUEL, 2014, p. 20). 
É possível situar a origem dessa separação entre governantes e governados - e sua legitimação - a partir da difusão das ideias contidas na obra do filósofo inglês John Locke (1980), conhecido como o pai do liberalismo político (um conjunto de princípios e valores que tinha como diretriz básica a limitação do poder político). Em obra clássica, a saber, Segundo tratado sobre o governo, de 1698, o autor postula um estado de natureza originário onde todos seriam livres e iguais; mas, como haveria inconvenientes que precisariam ser superados notadamente a ausência de um juiz imparcial - seria preciso reservar a alguns o monopólio do direito de fazer cumprir as leis, pois, caso contrário, e dada a igual capacidade de julgar e aplicar as leis no estado originário, reinaria a instabilidade e a insegurança, motivo para a produção do pacto e instauração da sociedade civil/política. Assim, segundo Locke, na tensão entre igualdade e liberdade, é preferível ficar com a segunda, pois, caso contrário, reinaria o caos, e isso era tudo o que se desejaria evitar. Desse modo, fica evidente, como se nota já na clássica formulação lockiana, que a igualdade, ao gerar inconvenientes, impede os indivíduos de usufruir de sua liberdade. Consequentemente, a desigualdade política não só é justificada, mas também "naturalizada", creditada como condição essencial para o bom funcionamento da sociedade (LOCKE, 1980).

Um segundo problema se refere a formação de uma elite política distanciada da massa da população, como consequência da especialização funcional. Como observa Miguel (2014), o "princípio da rotação" - governar e ser governado alternativamente -, fundamental nas democracias da antiguidade, não se aplicaria aqui, uma vez que o grupo governante tenderá a exercer permanentemente o poder. $\mathrm{O}$ terceiro problema diz respeito à ruptura do vínculo entre a vontade dos representantes e a vontade dos representados que se deve tanto ao fato de que os governantes tendem a possuir características sociais distintas dos governados, como também a mecanismos intrínsecos à diferenciação funcional. Pode-se afirmar que uma nova posição no espaço social - a de representante - gera a produção de novos interesses usualmente distintos dos interesses da base. Esse processo é fortalecido, segundo Miguel (2014), pelos mecanismos de cooptação presentes nas instituições e pela tendência à geração de um "espírito de corpo", isto é, de uma nova identidade, distinta daquela que caracteriza os representados. Esses três conjuntos de problemas, associados ao desvio do funcionamento esperado de nossas instituições democráticas, na percepção das pessoas comuns, têm levado a erosão da confiança nessas mesmas instituições (FERES Jr, J; EISENBERG, J., 2006; MOISÉS,2010).

No entanto, no mundo todo, estão surgindo novos debates sobre como "revitalizar" a democracia (GAVENTA, 2004). Nesse sentido, prospectar alternativas visando maior

Comun. \& Inf., Goiânia, GO, v. 21, n. 1, p. 51-69, jan./mai.. 2018 
aprofundamento/fortalecimento da democracia, isto é, buscar uma maior aproximação com o sentido normativo de autonomia coletiva vai ao encontro do que defendeu Boaventura de Sousa Santos, ao argumentar que a democracia não constitui um mero acidente ou uma simples obra de engenharia institucional, mas sim uma nova gramática histórica, passível, portanto, de aprendizagem continuada, tendo como ênfase o exercício cotidiano da participação e mobilização social (AVRITZER \& SANTOS,2002). É nesse contexto, portanto, que as ações comunicativas ganham relevo, quer como conceito, ligado ao construto "comunicação pública", quer como prática inseparável dos regimes democráticos contemporâneos. Desse modo, defende-se que ações e estratégias comunicativas, elaboradas e disseminadas pelas mais diversas instituições do Estado democrático - nas instâncias federal, estadual e municipal podem ser importantes ferramentas de aproximação e envolvimento do cidadão com os poderes públicos, contribuindo para o aprofundamento e o fortalecimento do sistema democrático. A questão que orienta e atravessa esta reflexão, portanto, pode ser colocada da seguinte forma: de que maneiras a comunicação pública de Estado contribui para a qualificação das instituições democráticas e, por extensão, do próprio regime democrático?

Assim, partindo da suposição de que o interesse público seja a base de sustentação do Estado democrático de direito, a comunicação pública - produzida e disseminada pelos entes públicos - desempenha importante papel na formulação, promoção, difusão, avaliação, julgamento e controle das ações desempenhadas pelos poderes públicos, favorecendo e fortalecendo a aproximação entre cidadãos e governos. Apesar de ser ainda um campo em construção, no entanto, é possível conceituar a Comunicação Pública como um "processo de comunicação que se instaura na esfera pública entre o Estado, o Governo e a Sociedade e que se propõe a ser um espaço privilegiado de negociação entre os interesses das diversas instâncias de poder constitutivas da vida pública no país” (BRANDÃO, 2007, p.18).

\section{TENTATIVAS DE QUALIFICAÇÃO DA DEMOCRACIA}

Há muitas maneiras de classificar as concepções de democracia e não existe consenso acerca de qual seria o melhor guia. Uma tentativa de taxionomia das concepções de democracia é a de C. B. Macpherson (1978), retomada (e reformulada) por David Held (1996). Grosso modo, seria possível distinguir uma corrente que privilegia o gozo dos direitos individuais, vendo a participação política, e em especial, o direito ao voto, como apenas um mecanismo de proteção contra o risco de despotismo dos governantes, e outra que, valorizando a participação

Comun. \& Inf., Goiânia, GO, v. 21, n. 1, p. 51-69, jan./mai.. 2018 
política por si mesma, vê nela um instrumento para o desenvolvimento das capacidades/competências cognitivas dos cidadãos. O primeiro grupo inclui autores tão diversos entre si quanto o segundo. A classificação proposta por David Held (1996) possui o mérito, porém, de enfatizar o caráter normativo presente em ambos os grupos, e é inspirada nela que pretendemos balizar a discussão.

Nessa perspectiva, a primeira abordagem que iremos analisar, conhecida como "Competitivo Elitista" (HELD, 1996), "Elitismo Democrático" (MELO, 2012; AVRITZER, 2011), ou "Democracia Concorrencial" (MIGUEL,2000;2014), se refere às concepções liberais hegemônicas, que reduzem a democracia a um método de seleção de governantes e consideram inviável qualquer presença popular mais efetiva na tomada de decisões políticas. Pode-se citar o diagnóstico esboçado pelo sociólogo alemão Max Weber como ponto de partida do modelo. Para Weber, com efeito, a crescente complexidade das sociedades modernas exigiu cada vez mais a transferência dos meios de administração e produção para o controle de funcionários especializados, com o consequente aumento do controle de tais funcionários sobre a vida dos indivíduos (WEBER, 1994) É por essa razão que muitos daqueles considerados adeptos de argumentos "realistas", que se dedicaram ao estudo da democracia no século XX, duvidaram acerca da plausibilidade de se encontrar efetivados os clássicos ideais democráticos, como o do bem comum, da soberania popular e da participação direta. No caso weberiano, a ruptura mais importante com as concepções clássicas de democracia, se dá a partir da substituição de um conceito holístico de racionalidade, cuja pretensão seria alcançar uma noção unificada acerca do bem comum, por um conceito técnico/instrumental de racionalidade, de acordo com o qual o aumento da complexidade das sociedades modernas apontaria na direção da continuidade da separação entre o conjunto de cidadãos comuns - o povo - e os meios de produção e administração. Diante de tal cenário, e sendo obrigado a lidar com tais condições, estreitadoras de soberania, é que a democracia passa a ser equiparada com a possibilidade, ou não, da extensão dos direitos políticos a todos os membros de um Estado nacional. Em outras palavras, democracia é equiparada à igualdade formal de direitos políticos.

É somente a partir das ideias do economista austríaco Joseph Schumpeter, no entanto, autor do clássico Capitalismo, Socialismo e Democracia, de 1942, que a tese da democracia concorrencial ganha impulso e se enraíza no senso comum. Com efeito, Schumpeter parte de preocupações semelhantes às de Weber para combater o que chama de duas grandes ficções da doutrina clássica de democracia, incapazes de resistir a uma análise "realista": a primeira grande ficção se assenta na noção de bem comum. Os adeptos da visão clássica partiam do pressuposto

Comun. \& Inf., Goiânia, GO, v. 21, n. 1, p. 51-69, jan./mai.. 2018 


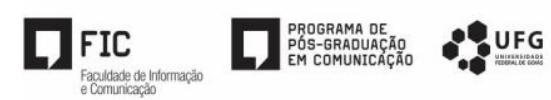

de que a democracia consistiria num arranjo institucional capaz de permitir que os indivíduos alcançassem um acordo acerca do significado do bem comum. O problema com essa definição é a suposição de que cada pessoa pudesse, por força de argumentos racionais, chegar a um acordo acerca do significado do bem comum. Essa imagem de um corpo político unificado contradizia abertamente o diagnóstico de uma sociedade pluralista, povoada por uma diversidade de valores e vontades individuais e, tal como Weber, Schumpeter também sabia que valores estão além do campo da lógica (WEBER, 1994; AVRITZER, 2011). Assim, a concepção clássica de democracia seria inadequada porque supôs a possibilidade de unificar, numa única perspectiva, a diversidade de valores, quando, na verdade, só é possível supor um procedimento para a convivência de pessoas diferentes.

Uma segunda grande ficção se refere a concepção clássica de indivíduo racional. O ataque à "vontade do povo" está ligado ao seu ceticismo quanto à possibilidade de que o "povo" seja realmente composto de indivíduos capazes de conduzir e justificar suas ações de modo autônomo e racional. A crítica do autor foi fortemente influenciada por estudos e reflexões acerca do comportamento de indivíduos em sociedades massificadas. Tais estudos, voltados originalmente para a dinâmica do mercado, apontaram a fragilidade dos consumidores diante das manipulações publicitárias. A suscetibilidade dos indivíduos-consumidores perante as investidas mercadológicas, portanto, serviria para exemplificar o comportamento dos cidadãos perante partidos políticos e governos, pois maiores seriam os motivos que levariam os cidadãos a se comportarem de forma semelhante na esfera política, já que: (a) dada a propensão de indivíduos de se interessarem menos pelas questões políticas do que pelas econômicas - já que um pressuposto implícito do modelo postula que os seres-humanos são "naturalmente" egoístas e, portanto, não dão a mínima para assuntos de interesse coletivo; e (b) dada a suas propensões a ceder a impulsos e preconceitos irracionais ou extrarracionais, já que os eleitores seriam simples "massa de manobra", não haveria como supor um comportamento racional de indivíduos na esfera política. Assim, devido à irracionalidade das massas e à impossibilidade de obter consensos racionais entre indivíduos autointeressados, a participação política não poderia ir além do momento da escolha das elites políticas e o único mecanismo racionalmente justificável de participação a que os cidadãos teriam real acesso seria o voto.

Para Schumpeter, portanto, democracia se reduz a uma luta entre líderes políticos rivais disputando pelo direito de governar. Em outras palavras, democracia é definida como um arranjo institucional cujo propósito é chegar a decisões coletivas em que certos indivíduos adquirem, por meio uma disputa competitiva pelo voto popular, o poder de decidir. Desse modo,

Comun. \& Inf., Goiânia, GO, v. 21, n. 1, p. 51-69, jan./mai.. 2018 


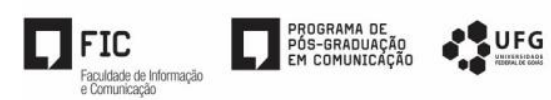

os únicos participantes integrais do sistema democrático schumpeteriano seriam os membros das elites políticas nos partidos e em cargos públicos. O papel do cidadão comum não só é fortemente diminuído, mas também frequentemente descrito como um obstáculo e até mesmo uma violação do processo de decisão pública regular (HELD, 1996). Assim, o "elitismo" expurga do referencial político-democrático a orientação republicana clássica em que todos os cidadãos tinham o dever de participar e compor a vida pública. (BARROS, 2012).

O balanço das contribuições de Weber e Schumpeter aponta, portanto, na mesma direção: ambos perceberam que o pressuposto da soberania entrava em choque tanto com as formas complexas de administração do Estado moderno quanto com a pluralidade de valores e orientações individuais. Ambos acreditaram também na necessidade de oferecer uma resposta formal ao problema da justificação da democracia. Weber apontou para a extensão dos direitos políticos, enquanto que Schumpeter propôs o consenso em torno do procedimento/método de seleção na formação do governo. No entanto, nenhum dos dois autores foi capaz de conectar a forma com a qual eles identificaram a prática da democracia com a ideia de racionalidade associada com a democracia desde a sua origem no período moderno. Weber não foi capaz de fazê-lo, pois, para ele, o único tipo de racionalidade com o qual o indivíduo poderia se identificar era uma racionalidade instrumental, sem qualquer valor em si mesma. Schumpeter também não foi capaz de fazê-lo porque ele negou a base individual-racional. A noção de racionalidade democrática, defendida por Schumpeter e por ele conferida aos membros das elites políticas, carece, portanto, de um critério que possa tornar o voto em determinada parcela das elites mais ou menos racional. Assim, sua teoria, ao prescindir da racionalidade dos agentes, deixa de tratar de forma adequada o modo como a democracia, entendida como forma racional de organização do Estado, seria capaz de compatibilizar o Estado com o indivíduo e com a sociedade (AVRITZER, 2011).

Uma estratégia alternativa de fundamentação teórica da concepção elitista surgida no período pós-guerra, foi desenvolvida por Anthony Downs em seu livro Uma teoria econômica da democracia, de 1957. Downs procurou preencher a lacuna deixada pela teoria schumpeteriana, ao não ter sido capaz, como vimos, de compatibilizar sua teoria da democracia com uma teoria da racionalidade individual. Downs propôs uma solução para esse problema ao identificar a ideia de racionalidade com a ideia de maximização de benefícios que o indivíduo pode extrair do sistema político. Com efeito, o autor modifica uma das premissas de Schumpeter ao postular que os cidadãos possuem, sim, interesses identificáveis e são capazes de perceber se eles estão, ou não, sendo atendidos. A partir, portanto, da introdução do axioma do

Comun. \& Inf., Goiânia, GO, v. 21, n. 1, p. 51-69, jan./mai.. 2018 


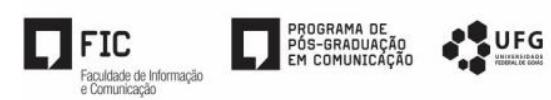

autointeresse, Downs pôde deduzir a conexão entre a racionalidade individual e a racionalidade global dos regimes democráticos: o indivíduo é racional porque busca maximizar os benefícios que o governo pode lhe oferecer; o sistema democrático é racional porque os partidos políticos e governos, ao pretenderem se manter no poder, buscam maximizar os benefícios que são capazes de proporcionar aos indivíduos-eleitores. Ao pressupor, no entanto, que governantes e eleitores se limitam a calcular o grau de aceitabilidade ao ofertarem certos benefícios, reduz-se a dinâmica complexa da política à previsibilidade estratégica que, geralmente, definiu - e define - a dimensão do mercado capitalista. No modelo de Downs, portanto, o "homo politicus" restaria reduzido e inteiramente subordinado ao "homo economicus" (MELO,2012).

Não há, portanto, na elaboração dowsiana, qualquer referência aos grandes intermediários do jogo político, como os grupos de interesse corporativos, os financiadores de campanha e a mídia de massa - essa também organizada de forma empresarial e portadora de interesses identificáveis - além do que se tem chamado de "comunicação pública de Estado", uma complexa rede de dispositivos informacionais e comunicacionais, abrangendo ONGs, partidos políticos, movimentos sociais, instituições públicas etc., tendo como princípio unificador a ideia de interesse público. Essa lacuna, no entanto, foi parcialmente preenchida e, mesmo assim, de maneira demasiadamente "reducionista", na abordagem do cientista político norte-americano Robert Dahl.

Mais sofisticada, a abordagem conhecida como "pluralista" (HELD,1996) ou “pluralismo democrático” (MELO,2012; MIGUEL,2000;2014; AVRITZER,2011) ocupa um lugar intermediário entre o "elitismo democrático" e uma concepção mais normativa e participativa da democracia. Como vimos, o modelo anterior de democracia descreveu os processos políticos priorizando basicamente dois atores representativos: as elites, de um lado, e os eleitores, de outro. No que se refere ao modelo downsiano, a justificação para fundamentar a legitimidade do regime democrático se ancorou prioritariamente na racionalidade individual. Uma explicação predominantemente utilitarista mostrou que indivíduos maximizam seus interesses e agregam suas preferências (preexistentes) para alcançar seus objetivos, subordinando, porém, a prática política coletiva à agregação de ações meramente individuais. Desse modo, se em Schumpeter há pouco ou nenhum espaço entre os cidadãos individuais e os líderes políticos, já que não há como escapar do caráter manipulador da disputa política eleitoral e, portanto, qualquer proposta destinada a aprimorar o esclarecimento dos votantes ou o aperfeiçoamento das instituições, é ingênua e inócua, em Downs, por outro lado, a dinâmica 


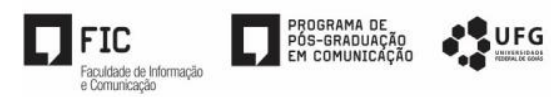

das políticas de grupo ficou limitada por uma orientação radicalmente individualista, reduzindo a decisão eleitoral à percepção não-mediada de suas condições de vida.

Robert Dahl, por outro lado, acredita, ao contrário, que ambas as concepções "realistas" são incompletas e parciais: a deficiência, nos dois casos, consiste em desconsiderar os grupos intermediários na descrição do jogo político e na justificação do regime democrático (HELD,1996; AVRITZER,2011; MIGUEL,2000;2014). Desse modo, toda a problemática em torno da democracia se resume em desvendar a lógica de distribuição do poder. Para o autor, poder pode ser definido como a capacidade de impor objetivos em face da oposição de outrem. Isso por que na concepção pluralista, o poder é arranjado de maneira não-hierárquica e competitiva, o que significa afirmar, em outras palavras, que é uma parte inextrincável de um processo infinito de barganha entre inúmeros grupos de interesse. Esses pressupostos projetam uma imagem da democracia, portanto, como estímulo e como garantia da competição entre inúmeros grupos de interesse, com a proteção de minorias e de direitos de participação (HELD,1996). Assim, o importante aqui é atentar para determinadas condições procedimentais que possam assegurar uma estabilidade justificável para a competição. É por essa razão que Dahl entenderá a democracia como um processo de tomada de decisões coletivas, processo esse garantido a partir de um procedimento racionalmente justificável. Na concepção dahlsiana de democracia, o ideal clássico de bem comum e da soberania popular é abandonado, tanto no que diz respeito aos aspectos homogêneos e unificadores da noção de bem comum, quanto da noção de democracia representativa enquanto governo da maioria. Ambos os casos seriam problemáticos, porque o caráter democrático do regime é assegurado pela existência de múltiplos grupos ou múltiplas minorias (HELD,1996).

No entanto, há dois elementos importantes em sua obra que representam uma ruptura com a concepção elitista. O primeiro desses elementos consiste na tentativa de superar a oposição insatisfatória entre idealismo e realismo, entre democracia ideal e democracia real. Ao lado do termo "poliarquia", que designa um conjunto de instituições, práticas e direitos efetivos que asseguram a competição entre inúmeros grupos de interesse, e que se impuseram nos estados nacionais modernos, a partir das revoluções americana e francesa, Dahl introduz um termo adicional na teoria democrática: o princípio da maximização. Segundo este autor, se o objetivo de estabelecer uma poliarquia democrática for realmente levada a sério, é preciso pensar em como ampliar a vigência de certos elementos dessas poliarquias. Não se trata de analisar como a democracia ou "poliarquia" é ou funciona, mas sim de perceber que uma avaliação ou correção de rota na forma como certas características das poliarquias se

Comun. \& Inf., Goiânia, GO, v. 21, n. 1, p. 51-69, jan./mai.. 2018 


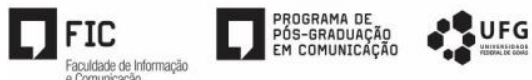

manifestam na realidade das sociedades contemporâneas, é fundamental para se avaliar o grau de igualdade e de liberdade efetivamente existente em tais sociedades (DAHL,2005; AVRITZER,2011). Em outras palavras, se Dahl assume, por um lado, que sistemas políticos ideais não existem, assume, por outro lado, a possibilidade das práticas democráticas existentes fornecer elementos para que toda tentativa de justificação se aproxime o mais possível do ideal. Para o autor, o processo democrático deveria proporcionar: (a) controle sobre as decisões governamentais tomadas por seus representantes; (b) eleições livres e periódicas; (c) inclusão de todas as pessoas e grupos envolvidos; (d) chances reais de participação no processo político repartidas equitativamente entre os grupos interessados; (e) igual direito ao voto nas tomadas de decisão; (f) direitos iguais no que diz respeito à escolha de temas e manutenção da agenda política; (g) condições de publicidade e transparência para que todos os interessados possam compreender as matérias controversas a serem regulamentadas. Desse modo, dado o princípio da maximização, isto é, a ampliação de determinadas formas institucionalizadas de participação nos processos democráticos, a oposição realismo/idealismo não se sustenta. $O$ segundo elemento de rompimento com a teoria elitista consiste na constatação do fato de que se a poliarquia realmente constitui uma forma de organização do sistema de governo, tal forma pode, de acordo com Dahl, ser mais ou menos legítima, dependendo do processo de discussão anterior à própria eleição. Essas condições, com efeito, permitem reinserir no interior da teoria democrática o problema da participação como requisito para avaliar a qualidade da poliarquia existente. Desse modo, como sublinhamos, é possível perceber em Dahl dois elementos centrais na crítica ao modelo elitista: o rompimento da oposição idealismo/ realismo e a preocupação com a qualidade da prática democrática.

Dahl procura definir a democracia como algo mais do que um sistema de governo. Para o autor, democracia constitui um processo de tomada de decisões coletivas. Como vimos, Dahl continua reservando ao termo democracia uma forma de organização política ideal com a qual as sociedades modernas "reais" não podem ser comparadas. No entanto, esse ideal não impede a sua avalição normativa, uma vez que Dahl inverte os termos da avaliação tal como proposto pelo elitismo: não é o que foi idealizado que deve ser criticado, mas o fato das democracias reais não serem capazes de alcançar o ideal democrático. Desse modo, uma teoria que tentasse conciliar o empírico e o normativo teria como tarefa restaurar o ideal da autonomia moral e a justificativa normativa do sistema democrático, buscando demonstrar a importância desses ideais na prática democrática. Dahl demonstra tal possibilidade em duas etapas distintas, uma primeira na qual discute os fundamentos morais da democracia e uma segunda na qual discute

Comun. \& Inf., Goiânia, GO, v. 21, n. 1, p. 51-69, jan./mai.. 2018 


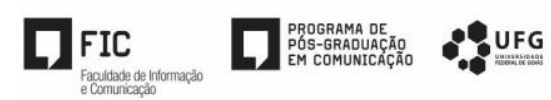

a realidade empírica dos países que se tornaram poliarquias democráticas. Para os propósitos deste trabalho, no entanto, vamos nos ater apenas à primeira etapa.

Assim, ao discutir as formas possíveis de justificação da democracia, Dahl primeiramente parte do suposto de que a democracia, sempre que comparada com os outros sistemas de governo, tende a ser o melhor modo de organização do Estado. No entanto, como observou Avritzer (op. cit), embora Dahl forneça um critério empírico capaz de colocar a democracia em posição de destaque face a sistemas não democráticos, esse método não é suficiente para justificar aos olhos dos atores políticos a desejabilidade da democracia. Com efeito, esse constitui o motivo da reintrodução pelo autor do princípio da autonomia moral no interior da teoria democrática. Desse modo, o autor sustenta não apenas que a participação democrática é afim ao desenvolvimento moral, recolocando na teoria democrática um elemento ausente desde Schumpeter, como deduz desse princípio uma crítica ao elitismo. Para o autor, o princípio da autonomia moral traz, como consequência, a constatação de que todos os indivíduos são suficientemente qualificados para participar das decisões coletivas, vinculando-se às associações que possam afetar seus bens e interesses. Assim, o princípio da autonomia moral implica tanto uma ruptura com a visão schumpeteriana quanto da versão dowsiana do "elitismo democrático", na medida em que recoloca um fundamento moral no centro da teoria democrática ao mesmo tempo em que rompe com a noção limitadora de racionalidade enquanto maximização de benefícios materiais.

Há, todavia, dois elementos na formulação dahlsiana que merecem destaque. O primeiro deles é a redução da política a um processo de escolha a partir de interesses individuais preexistentes. Com efeito, embora considere que todos os cidadãos são guiados por um entendimento esclarecido de seus interesses (DAHL,2005; MIGUEL,2000), isto é, que possuem a capacidade de compreender e definir aquilo que desejam, o processo de produção dos interesses e de formação das preferências — ou seja, das vontades e identidades coletivas — é eliminada da esfera pública política. O segundo ponto é que, embora Dahl dê um passo relevante para incorporar os meios de comunicação em sua abordagem, ao colocar o acesso igual à informação como um dos requisitos para o perfeito funcionamento da democracia, e mesmo admitindo que esta condição nunca é plenamente preenchida, parece julgar que a simples ausência de censura estatal seria suficiente para proteger os direitos dos cidadãos à informação ampla e variada (MIGUEL, 2000). É que Dahl opera uma segunda redução: a da comunicação à informação, isto é, ao provimento ou a "divulgação" de dados "objetivos" sobre a realidade. Desse modo, como observou Avritzer (Op.Cit), ao associar a justificação normativa 
da democracia com as condições que propiciam a auto realização moral individual, o aspecto comunicativo próprio à atividade política é esvaziado. Em outras palavras, não há, em Dahl, uma concepção normativa de sociedade. Escapa ao autor, portanto, a dimensão normativa da democracia enquanto valor coletivo compartilhado por uma associação de indivíduos capazes de estabelecer formas comuns de ação (AVRITZER, 2011).

Por outro lado, e como contraponto ao modelo hegemônico de fundo liberal, o modelo "participativo" (HELD, 1996) ganhou corpo a partir dos movimentos contestatórios da década de $60^{3}$. Trata-se de uma corrente teórica conhecida como "nova esquerda" e toma como ponto de partida a intuição original de Marx segundo a qual o mercado capitalista cristaliza as desigualdades materiais anteriormente produzidas, sendo a mais importante aquela entre os possuidores dos meios de produção e os que são obrigados a vender sua força de trabalho. Assim, o foco do modelo se volta não apenas para a tentativa de superação das desigualdades materiais, desigualdades essas que impedem ou limitam a realização efetiva de liberdades, como também para a diminuição dos déficits de formação política da opinião e da vontade que daí resultam, o que significa antes de mais nada buscar formas alternativas de ampliação da participação nos processos decisórios. É um modelo de democracia, portanto, que aponta para além das instituições políticas representativas, ao postular não apenas a ampliação da participação nos processos decisórios, mas também sua expansão para outras instâncias da vida coletiva.

Incorporando parte significativa do ideal participacionista, mas apresentando uma nova ênfase nos mecanismos discursivos da prática política, a abordagem representada pelos chamados “democratas deliberativos" (HELD, 1996; MELO, 2012; NOBRE, 2004; MIGUEL, 2000;2014) trata das concepções que acentuam o aspecto de debate público como inseparável do projeto democrático. Segundo David Held (Op.Cit), o primeiro impulso teórico para o debate parece ter sido dado por Bernard Manin, ao distinguir dois sentidos da noção de "deliberação" - como "processo de discussão" e como "decisão" - e ao fazer o segundo sentido depender teórica e praticamente do primeiro. Com isso, coube a Joshua Cohen (1997) formular pela primeira vez o que viria a ser o núcleo dessa corrente teórica. Com efeito, para este autor, a concepção de democracia deliberativa estaria organizada em torno de um ideal de justificação

\footnotetext{
${ }^{3}$ Suas principais referências foram os trabalhos de Nikos Poulantzas, Carole Paterman e C.B. Macpherson. Ver POUlantZAS, Nico. Poder Político e Classes Sociais: Rio de Janeiro: Jorge Zahar, 1968; PATERMAN, Carole. Participação e Teoria democrática. Rio de Janeiro: Paz e Terra,1992 e MACPHERSON, C.B. A democracia Liberal: origens e evolução: Rio de Janeiro: Jorge Zahar,1978
}

Comun. \& Inf., Goiânia, GO, v. 21, n. 1, p. 51-69, jan./mai.. 2018 


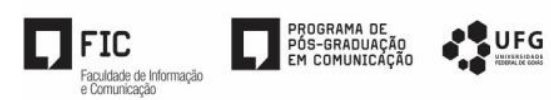

política. De acordo com esse ideal, justificar o exercício do poder político coletivo é proceder com base na argumentação pública livre entre iguais. Uma democracia deliberativa institucionaliza esse ideal. Por essa razão, a ideia básica implícita no modelo é a de que somente podem ser ditas válidas (isto é, vinculadas moralmente) aquelas normas (isto é, tanto regras gerais de ação, quanto determinados arranjos institucionais) que recebessem a anuência de todos aqueles afetados por suas consequências, considerando que tal acordo fosse alcançado como o resultado de um processo de deliberação que tenha as seguintes características: (1) estar franqueada a todos, sem exceção; (2) levar em conta apenas a argumentação racional, isto é, não admitir a influência de posições de autoridade, riqueza, status etc, o que significa garantir a igualdade entre todos os participantes; e (3) se encontrar numa situação em que os participantes buscam atingir o consenso, ou seja: estão dispostos a assimilar os argumentos dos outros e não se prendem a posições prévias. Não há regras, portanto, que limitem a agenda da conversação, ou a identidade dos participantes, contanto que cada pessoa possa demonstrar e justificar que são afetados de modo relevante pela norma proposta. (HELD, 1996; NOBRE, 2004; MIGUEL, 2000; 2014).

Da mesma forma que a vertente participativa, a deliberativa se apresenta como um modelo normativo que produz a crítica da política vigente a partir de um parâmetro ideal. Esse ideal, porém, remete a uma matriz histórica - ou pseudo-histórica - a "esfera pública burguesa", descrita e narrada pelo filósofo alemão Jürgen Habermas, em uma de suas obras mais influentes, a saber, "Mudança estrutural da esfera pública", tese de 1962. Nesse trabalho, a partir de uma reflexão sobre o surgimento da opinião pública na França, na Alemanha e, sobretudo, na Inglaterra, nos séculos XVIII e XIX, o filósofo apresenta uma visão da "boa política", caracterizada pela discussão livre de questões de interesse coletivo. Os cafés ingleses seriam o emblema deste universo, local onde os homens - mas não as mulheres - conversariam entre si em pé de igualdade, assumindo que os problemas públicos interessavam a todos e, como tal, podiam ser discutidos, de forma legítima, por todos os participantes. A imprensa funcionava como elo entre os múltiplos debates travados nos diferentes cafés e salões. Contra o pano de fundo desse ideal normativo, o autor lamenta a decadência da esfera pública "atual", refém das estratégias de manipulação publicitárias (HABERMAS, 2014). Em obra seguinte, Habermas deixa provisoriamente de lado - e só o retoma em trabalho posterior - o conceito de esfera pública, substituindo-o, porém, por um outro análogo, embora no contexto de uma teoria mais abstrata: o conceito de ação comunicativa. O ideal normativo que guia agora sua reflexão é a ação voltada para o entendimento mútuo, por meio do diálogo, em contraposição à ação 


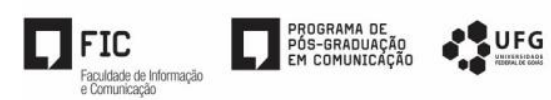

estratégica, que busca apenas o sucesso e utiliza caracteristicamente operadores sistêmicos como o poder e o dinheiro. (MIGUEL, 2014; HABERMAS,2012).

A reflexão de Habermas toma como ponto de partida problemas semelhantes àqueles levantados por Weber e Schumpeter, isto é, o crescimento das arenas burocrático-administrativas e a impossibilidade e indesejabilidade de uma ideia substantiva de bem comum. Ambas as preocupações são relacionadas pelo autor ao problema da racionalidade, mas recebem uma resposta fundamentalmente distinta da resposta dada por Weber e Schumpeter. Para Habermas, a existência de dois tipos de racionalidade (uma "comunicativa", de natureza intersubjetiva, e uma outra "sistêmica", de natureza cognitivo-instrumental) permitiria tratar adequadamente tanto o fenômeno da burocratização quanto o fenômeno da pluralização. Os dois fenômenos, no entanto, teriam raízes distintas e se localizariam em esferas distintas de sociabilidade. A burocratização estaria associada à racionalidade sistêmica e seria dominante na esfera administrativa do Estado moderno, esfera essa estruturada em torno da lógica estratégicocompetitiva e de uma forma impessoal de coordenação da ação. A expansão da influência de tal forma de ação certamente conduziria a uma diminuição da autonomia dos indivíduos frente ao Estado moderno, como já havia notado Weber. Porém, diferentemente do suposto por Weber, esse não constituiria no único fenômeno com o qual a política moderna estaria associada. Com efeito, a partir do pressuposto de que na modernidade ocidental ocorreu um processo primário de diferenciação das estruturas de racionalidade que dissociou a complexificação das estruturas que chamou de "sistêmicas" - o "subsistema" administrativo e o "subsistema" econômico - de outro modelo, que qualifica de processo de racionalização comunicativa das estruturas do "mundo da vida", Habermas procura demonstrar a existência de uma forma distinta de racionalidade capaz de nutrir e fortalecer as formas interativas de comunicação com as quais a democracia foi identificada pelos teóricos da política moderna. Assim, a racionalidade comunicativa não estaria associada a esfera do Estado, mas sim a esfera pública, entendida enquanto uma arena discursiva na qual os valores democráticos se formam e se reproduzem (HABERMAS, 1995; 2014; AVRITZER, 2011). Desse modo, o modelo deliberativo não aceita reduzir a democracia à sua forma de organização político-estatal, particularmente ao sistema partidário. Mais que isso, aponta para uma maneira de compreender a democracia como uma forma de vida (AVRITZER \& SANTOS,2002; AVRITZER, 2011) ou, num outro registro, como uma "tradição" (ALVES; RABELO; SOUZA, 2014; GADAMER, 1996). 


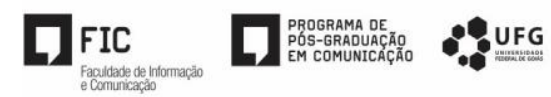

Não há dúvida de que na concepção deliberativa está presente um esforço importante no sentido de procurar superar o pretenso empirismo das concepções anteriores. Em primeiro lugar, essa corrente rompe com o entendimento da democracia como simples método para a agregação de preferências individuais preexistentes. Ela postula, ao contrário, que longe de constituírem em elementos prévios, as preferências são configuradas e reconfiguradas nas interações entre os participantes do debate político nas esferas públicas. Em segundo lugar, há a ênfase na igualdade da participação, um aspecto constitutivo do sentido clássico de democracia, mas negligenciado pelas teorias hegemônicas predominantes. E, por fim, a autonomia - a produção de normas pelos próprios integrantes, é resgatada como valor fundamental que guia o projeto democrático (MIGUEL, 2000; 2014).

Porém, como observou Miguel (2000; 2014), quando Habermas deixa de considerar a esfera pública como centro de suas preocupações em prol da teoria do agir comunicativo, também os meios de comunicação deixam seu horizonte de preocupações e, em seu lugar, resta apenas a fala abstrata, cujo modelo é, desde sempre, a conversa interpessoal direta, tal como ocorreria no "mundo da vida", livre da influência dos operadores sistêmicos - o dinheiro e o poder - e "naturalmente" predisposta ao consenso. Desse modo, como colocado na introdução desse artigo, não é possível imaginar que a deliberação democrática em sociedades complexas, extensas e populosas, como a nossa, possa se dar através da comunicação interpessoal direta, sem a necessidade de mediações. A comunicação face a face não é, portanto, um modelo apropriado para o entendimento da política, exatamente por descartar não apenas a questão da representação política, mas também por ignorar uma característica de suma importância, mas que permaneceu à margem das formulações teóricas em democracia: o papel desempenhado pelos meios de comunicação de massa e de sua centralidade na conformação da sociabilidade contemporânea. Como afirmou o sociólogo britânico John B. Thompson, a "midiação" da cultura e da política moderna é característica inseparável das sociedades contemporâneas (THOMPSON,2011).

\section{CONSIDERAÇÕES FINAIS}

O desenvolvimento vertiginoso dos meios de comunicação de massa, ocorrido ao longo do século XX, modificou todo o ambiente político. O contato entre líderes políticos e sua base, a relação dos cidadãos com o universo das questões públicas e mesmo o próprio processo de governar, sentiram o poderoso impacto provocado pela revolução tecnológica nos processos

Comun. \& Inf., Goiânia, GO, v. 21, n. 1, p. 51-69, jan./mai.. 2018 


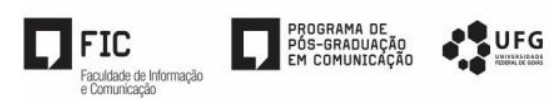

informacionais e comunicacionais contemporâneos. Poder-se-ia supor, assim, que, diante de tal evidência, os cientistas políticos e demais cientistas sociais seriam forçados a repensar seus modelos analíticos. Infelizmente, porém, não foi o que aconteceu. Como procuramos mostrar nesse artigo, as principais correntes teóricas de democracia foram incapazes de incorporar os meios de comunicação de massa em seus universos de reflexão. Como observou Miguel (2002), os cientistas políticos, por um lado, tenderam a restringir a importância da mídia, e os estudiosos da comunicação, por outro lado, costumaram exagerá-la, a ponto de julgar que a política, totalmente dominada pela lógica dos "meios", tornava-se um mero espetáculo entre outros. Essa é, de fato, uma afirmação que, a despeito de conter alguma razoabilidade, leva a ignorar a permanência de uma lógica especificamente política, cujas ações se desenrolam agora no interior de um quadro cada vez mais dominado pelos dispositivos comunicacionais e informacionais massivos. É fato inegável, portanto, que os meios de comunicação se tornaram centrais nas disputas pela produção de representações, crenças, ideias e imagens legítimas acerca do mundo social, fornecendo, nessa disputa, critérios para aferição de atitudes e comportamentos (GOMES, 2004; WEBER, 2004; 2006).

Pode-se igualmente argumentar que a influência dos meios de comunicação é também particularmente sensível num momento crucial do jogo político: a definição da agenda. Isso significa dizer que a pauta de questões relevantes, postas em circulação para a deliberação pública, é, em grande parte, condicionada pela visibilidade de cada questão nos meios de comunicação (WEBER, 2006). Dito de outra maneira, a mídia possui a capacidade de poder determinar o que deve ser objeto de preocupação pública. Nesse sentido, portanto, o universo da mídia não são canais neutros que "registram" uma realidade que lhes é externa, nem são simples “meios", interpostos entre as instituições políticas e a sociedade (GOMES, 2004). São agentes políticos plenos e, com a força de sua influência, são capazes de reorganizarem todo o jogo político. Por outro lado, não se deve deduzir do reconhecimento da influência da mídia sobre a esfera política à subordinação absoluta desta aos meios de comunicação. Os efeitos da mídia são diversos e variados, dependem do contexto em que se inserem e sofrem a ação de contra tendências e resistências. Há um processo permanentemente tensionado entre as lógicas do campo midiático e do campo político, que precisa ser observado em detalhe e dentro da complexidade de cada situação. Decretar, portanto, que a política "se curvou" à mídia é tão inapropriado quanto negar a influência desta sobre a primeira.

Nesse artigo, fez-se breve menção à comunicação pública de Estado, como consistindo numa complexa rede de dispositivos informacionais e comunicacionais que produz e faz 
circular valores, crenças, representações e visões de mundo acerca da realidade social. O desafio para a uma teoria de democracia que se disponha a incorporar os meios de comunicação em seu universo de reflexão é compreender como se organiza esse campo de produção e circulação/difusão de formas simbólicas e como valores, crenças, visões de mundo etc., são apropriados e incorporados por sujeitos políticos individuais e coletivos em suas práticas cotidianas. Entre os processos de produção, circulação e apropriação de formas simbólicas, os caminhos, seguramente, não são lineares; há desvios, tensões e contradições numa complexa trama de mediações (THOMPSON, 2011; BERGER, P. \& LUCKMAN, T., 1998; WEBER, 2004; 2006).

\section{REFERÊNCIAS BIBLIOGRÁFICAS}

ALVES, P.C; RABELO, M.; SOUZA I.M. Hermenêutica-fenomenológica e Compreensão nas Ciências Sociais. Revista Sociedade e Estado, Vol. 29, n.1, p.181-198, jan./abril 2014. Disponívelem $<\mathrm{https} / /$ :www.scielo.br/scielo.php?script=sci_serial\&pid=01026992\&lng=pt\&nr $\underline{m=i s o \& r e p}>$. Acesso em: 03 jan.2017

AVRITZER, Leonardo. A Moralidade da Democracia. São Paulo: Perspectiva, 2011

AVRITZER, L. SANTOS, B.S. Para Ampliar o Cânone Democrático. In: SANTOS, Boaventura Souza (Org.). Democratizar a democracia: os caminhos da democracia participativa. Rio de Janeiro: Civilização Brasileira, 2002.

BARROS, Alberto Ribeiro Gonçalves de. Republicanismo. In: RAMOS, F.C.; MELO, R.; FRATESCHI, Y. (Org.). Manual de Filosofia Política. São Paulo: Saraiva,2012.

BERGER, P.L. LUCKMAN, T. A Construção Social da Realidade. Petrópolis, RJ: Vozes, 1998

BRANDÃO, Elizabeth. Pazito. O Conceito de Comunicação Pública. In: DUARTE, J. (Org.). Comunicação pública: estado, mercado, sociedade e interesse público. São Paulo: Atlas, 2007.

COHEN, J. Deliberation and democratic legitimacy. In: BOHMAN,J.;REHG,W (org.). Deliberative democracy. Cambridge: MIT Press,1997. p.67-92

DAHL, R. Poliarquia: Participação e Oposição. São Paulo: Edusp, 2005

DOWNS, Anthony. Uma Teoria Econômica da Democracia. São Paulo: Edusp, 2015

FERES JR. J.; HEISENBERG, J. Dormindo com o inimigo: uma crítica ao conceito de confiança. DADOS, Revista de Ciências Sociais, Rio de Janeiro, Vol.49, n³, p.457-481, 2006. Disponível em < https//: http://www.scielo.br/scielo.php?script=sci_issues\&pid=00115258\&lng=pt\&nrm=iso $>$ Acesso em: 03 jan. 2017 
GADAMER, H.G. O Problema da Consciência Histórica. São Paulo: FGV, 1996

GAVENTA, J. Prefácio. In: COELHO, Vera Schattan P. e NOBRE, Marcos (Orgs.). Participação e deliberação: teoria democrática e experiências institucionais no Brasil contemporâneo. São Paulo: Editora 34,2004.

GOMES, W. Transformações da política na era dos meios de comunicação de massas. São Paulo: Paulus, 2004.

HABERMAS, Jürgen. Mudança Estrutural da Esfera Pública. São Paulo: Unesp, 2014

$\mathrm{n}^{\circ} 36,1995$.

Três Modelos Normativos de Democracia. São Paulo: Lua Nova, Teoria do Agir Comunicativo. São Paulo: Martins fontes, 2012

HELD, David. Models of Democracy. Stanford: Stanford University Press, 1996.

LOCKE, J. Segundo Tratado sobre o Governo. São Paulo: Abril Cultural,1980.

MACPHERSON, C.B.A democracia Liberal: origens e evolução: Rio de Janeiro: Jorge Zahar,1978

MELO, Rúrion. Teorias Contemporâneas da Democracia: Entre o Realismo Político e Concepções Normativas. In: RAMOS, F.C.; MELO, R.; FRATESCHI, Y. (Orgs.). Manual de Filosofia Política. São Paulo: Saraiva,2012.

MIGUEL, Luís Felipe. Introdução - Igualdade e Democracia no Pensamento Político. In: MIGUEL, L. F. (Org.). Desigualdade e Democracia. O Debate da Teoria Política. São Paulo: Unesp, 2015.

MIGUEL, Luís Felipe. Democracia e representação: territórios em disputa. São Paulo: Unesp, 2014. . Um ponto cego nas teorias da democracia: os meios de comunicação. BIB, Revista Brasileira de Informação Bibliográfica em Ciências Sociais, Rio de Janeiro, n.49, p.51-77,2000. Disponível em:

$\langle$ https//:www.anpocs.com/index.php/universo/acervo/biblioteca/periodicos/bib > Acesso em: 03jan.2017

Os meios de comunicação e a prática política. Lua Nova, Revista de

Cultura e Política, n. 55-56, p.155-184, 2002. Disponível em: https://www.cedec.org.br/luanova/publicacoes/ . Acesso em:03 jan.2017

MOISÉS, José Álvaro (Org.) Democracia e Confiança. Por que os Cidadãos Desconfiam das Instituições Públicas? São Paulo: Edusp, 2010.

NOBRE, Marcos. Participação e Deliberação na Teoria Democrática: Uma Introdução. In: COELHO, Vera Schattan P. e NOBRE, Marcos (Orgs.). Participação e deliberação: teoria 
口ir

democrática e experiências institucionais no Brasil contemporâneo. São Paulo: Editora 34, 2004.

SCHUMPETER, Joseph. Capitalismo, Socialismo e Democracia. Rio de Janeiro: Jorge Zahar, 1984.

THOMPSON, John B. Ideologia e cultura moderna: teoria social crítica na era dos meios de comunicação de massa. Petrópolis, RJ: Vozes, 2011.

WEBER, M. Economia e Sociedade. Brasília: UNB,2002.

WEBER, M. O Socialismo In: Gertz, R. Max Weber e Karl Marx. São Paulo: Hucitec, 1994

WEBER, Maria Helena. Imagem Pública In: RUBIM, Antônio Canelas A. (Org.). Comunicação e Política: conceitos e abordagens. Salvador: Edufba, 2004.

Visibilidade e Credibilidade: tensões da comunicação política. In: MAIA, Rousiley Celi Moreira; CASTRO, Maria Céres Pimenta Spínola. Mídia, esfera pública e identidades coletivas. Belo Horizonte: Editora UFMG, 2006. 